\title{
Coupling $\mathrm{X}$-band dual-polarized mini-radars and hydro-meteorological forecast models: the HYDRORAD project
}

\author{
E. Picciotti ${ }^{1}$, F. S. Marzano ${ }^{2}$, E. N. Anagnostou ${ }^{3}$, J. Kalogiros ${ }^{4}$, Y. Fessas ${ }^{5}$, A. Volpi $^{6}$, V. Cazac ${ }^{7}$, R. Pace ${ }^{8}$, G. Cinque ${ }^{1}$, \\ L. Bernardini ${ }^{1}$, K. De Sanctis ${ }^{1}$, S. Di Fabio ${ }^{1}$, M. Montopoli ${ }^{2,9}$, M. N. Anagnostou ${ }^{5}$, A. Telleschi ${ }^{6}$, E. Dimitriou ${ }^{10}$, and \\ J. Stella ${ }^{3}$ \\ ${ }^{1}$ HIMET srl, SS 17 Ovest n.36, L'Aquila, Italy \\ ${ }^{2}$ CETEMPS, University of L'Aquila, L'Aquila, Italy \\ ${ }^{3}$ University of Connecticut, Storrs, Connecticut, USA \\ ${ }^{4}$ NOA National Observatory of Athens, Athens, Greece \\ ${ }^{5}$ PROPLAN, Str. Ergates Industrial Estate, Nicosia, Cyprus \\ ${ }^{6}$ ELDES srl, Via di Porto 2/b, Scandicci (FI), Italy \\ ${ }^{7}$ SHS Serviciul Hidrometeorologic de Stat, Chisinau, Moldova \\ ${ }^{8}$ MICC Camera de Comert Italo-Moldava, Chisinau, Moldova \\ ${ }^{9}$ Department of Geography, University of Cambridge, Cambridge, UK \\ ${ }^{10}$ HMCR Hellenic Centre for Marine Research, Athens, Greece
}

Correspondence to: E. Picciotti (errico.picciotti@himet.it) and F. S. Marzano (marzano@die.uniroma1.it)

Received: 28 August 2012 - Published in Nat. Hazards Earth Syst. Sci. Discuss.: -

Revised: 19 February 2013 - Accepted: 11 March 2013 - Published: 16 May 2013

\begin{abstract}
Hydro-meteorological hazards like convective outbreaks leading to torrential rain and floods are among the most critical environmental issues world-wide. In that context weather radar observations have proven to be very useful in providing information on the spatial distribution of rainfall that can support early warning of floods. However, quantitative precipitation estimation by radar is subjected to many limitations and uncertainties. The use of dual-polarization at high frequency (i.e. X-band) has proven particularly useful for mitigating some of the limitation of operational systems, by exploiting the benefit of easiness to transport and deploy and the high spatial and temporal resolution achievable at small antenna sizes. New developments on X-band dual-polarization technology in recent years have received the interest of scientific and operational communities in these systems. New enterprises are focusing on the advancement of cost-efficient mini-radar network technology, based on highfrequency (mainly X-band) and low-power weather radar systems for weather monitoring and hydro-meteorological forecasting.

Within the above context, the main objective of the HYDRORAD project was the development of an innovative
\end{abstract}

integrated decision support tool for weather monitoring and hydro-meteorological applications. The integrated system tool is based on a polarimetric X-band mini-radar network which is the core of the decision support tool, a novel radar products generator and a hydro-meteorological forecast modelling system that ingests mini-radar rainfall products to forecast precipitation and floods.

The radar products generator includes algorithms for attenuation correction, hydrometeor classification, a vertical profile reflectivity correction, a new polarimetric rainfall estimators developed for mini-radar observations, and short-term nowcasting of convective cells. The hydrometeorological modelling system includes the Mesoscale Model 5 (MM5) and the Army Corps of Engineers Hydrologic Engineering Center hydrologic and hydraulic modelling chain. The characteristics of this tool make it ideal to support flood monitoring and forecasting within urban environment and small-scale basins. Preliminary results, carried out during a field campaign in Moldova, showed that the mini-radar based hydro-meteorological forecasting system can constitute a suitable solution for local flood warning and civil flood protection applications. 


\section{Introduction}

The inherent spatial and temporal variability of precipitation makes rainfall one of the most difficult geophysical variables to measure anywhere, and yet it is one of the most important for advancing hydro-meteorological predictions. In particular, improving local flood and flash flood forecasting requires accurate quantitative rainfall information at small temporal (minutes) and spatial (hundreds of meters) scales (Meischner et al., 1997). Arguably, weather radar's capability to monitor precipitation at high spatial and temporal scales has stimulated great interest and support within the hydro-meteorological community (Ivanov et al., 2004; Hossain et al., 2004).

Meteorological services across Europe are using networks of weather surveillance radars, which can advance precipitation monitoring with direct implications on the improvement of real-time forecasting of river floods and flash floods in ungauged basins (Ventura et al., 2012). Precipitation, though, may originate from varying meteorological systems, ranging from cold frontal systems to thunderstorms, and maritime systems, where rainfall estimates based on these classical single polarization radar observations have quantitative limitations. These limitations arise from uncertainties associated with rain-path attenuation, the lack of uniqueness in reflectivity-to-rainfall $(Z-R)$ transformation, radar calibration and contamination by ground returns problems, as well as precipitation profile and complex terrain effects (Meischner et al., 1997; Marzano et al., 2004).

Recent considerations concern the upgrade of those systems to include dual-polarization capability, expected to moderate the effect of attenuation, $Z-R$ variability, and radar calibration (Zrnic and Ryzhkov, 1999; Testud et al., 2000; Bringi and Chandrasekar, 2001), while locally deploying small radar units is an option to fill up critical gaps in the operational radar networks. Along this line, the use of cost effective low-power X-band radar units is particularly stressed in cases of regions prone to localised flood-inducing convective storms, over mountainous basins not well covered by operational radar networks (due to terrain blockage) and in urban regions in need of high resolution rainfall data to support flood management systems (Anagnostou et al., 1999; Matrosov et al., 2002; Anagnostou et al., 2004, 2005; Park et al., 2005; Marzano et al., 2010). X-band radars provide a possible tool in hydrologic forecasting for urban areas and small-scale basins. X-band radar is less expensive than longer wavelength radars as it requires a smaller dish and lower power to attain the requisite resolution and backscatter from precipitation. The drawback is that X-band signals may be heavily attenuated in intense rainfall and hail, such as that found in convective systems.

Current research on X-band rainfall measurements shows that the fundamental issue of rain-path signal attenuation at this frequency can be mitigated using differential phase shift $\left(\Phi_{\mathrm{dp}}\right)$ information (either directly or as a constraint)
(Anagnostou et al., 2005, 2006; Matrosov et al., 2005; Park et al., 2005; Vulpiani et al., 2005). Furthermore, due to increased sensitivity of $\Phi_{\mathrm{dp}}$ to precipitation intensity (about three times that of S-band radar) measurements at X-band may achieve higher resolution rain rate estimations than the lower frequency (C-band and S-band) measurements, which is one of the critical issues for local flood prediction applications.

However, there are several features of the X-band radar measurements that need to be explored to understand the full potential of this instrument in hydro-meteorology. These include: (1) the effect of rain-path attenuation correction uncertainty on the accuracy of rain estimation and hydrometeor classification; (2) the relative accuracy of low-power X-band retrieval of rain rates at high resolution relative to lower frequency (C-band and S-band) high-power polarimetric radar measurements; (3) the consequential impact on flood prediction accuracy in small scale basins; (4) the effect of vertical profile of reflectivity or rain (VPR) correction in mountainous terrain; and (5) the retrieval of hydrometeor water contents, critical in the study of precipitation microphysics and validation of satellite remote sensing of precipitation.

In the framework of the HYDRORAD project, we developed and assessed an innovative integrated system for weather monitoring and hydro-meteorological applications that tackles some of the above issues (Picciotti et al., 2012). The integrated system is based on an optimised polarimetric X-band mini-radar (i.e. low power, small-size) network, a software-based radar product generator for data quality control, dual-polarization radar-rainfall estimation, nowcasting and precipitation classification coupled with hydrological and meteorological models that integrate precipitation data retrieved from the mini-radar network. The system was demonstrated during the Moldova Operational Field (MOF) campaign that took place in autumn 2011 in Moldova.

Preliminary results from the MOF campaign are presented in this study, focusing on algorithmic, technological and applicability issues. This paper is organised as follows. In Sect. 2 we discuss the MOF campaign, where the three miniradar systems and related products generation algorithms and forecast tools were tested and compared against a state-ofthe-art X-band dual-polarization and Doppler radar (XPol) and in situ hydrological (Doppler flow meter, stream gauge) and meteorological (raingauges and disdrometer) stations. In Sect. 3 we focus on the description of the three X-band polarimetric radar system (two fixed and one mobile) that were optimised in terms of system specifications, manufactured and deployed in the HYDRORAD project. In Sect. 4 we describe the algorithms used to invert the $\mathrm{X}$ band polarimetric radar measurements into hydro-meteorological products, while in Sect. 5 we describe the integrated tool for short-tomedium-range forecasting using coupled hydrological models, a meteorological model and the mini-radar network observations from MOF. Finally, a summary and prospects for future research is discussed in Sect. 6. 


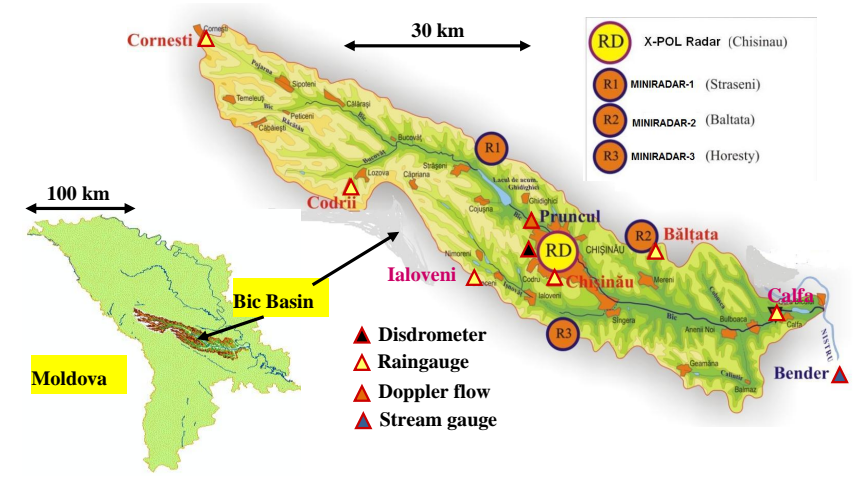

Fig. 1. The Bic basin location in Moldova and detail of the Bic river basin showing locations of the three mini-radar systems (R1 at Straseni, R2 at Baltata and R3 at Horesti), location of XPol radar (RD at Chisinau), and locations of the in situ stations: raingauges, disdrometer and hydrological instruments.

\section{HYDRORAD Moldova field operational (MOF) campaign}

In order to test the integrated system a two-month long experimental campaign took place during autumn 2011 in Moldova (Picciotti et al., 2012). The campaign area was centered on the Bic river basin (Fig. 1) which flows through the capital city Chisinau. Bic is a large river basin (area of $2131 \mathrm{~km}^{2}$ ) representing an region that frequently floods, affecting a large population in Moldova (located in and around the capital city). The experimental basin is represented by a mild altitude range (100 to $300 \mathrm{~m}$ a.s.l.). It is worth mentioning that the Bic river basin is an important resource in central Moldova for which the central government is looking for a better hydrological management system.

Three newly built dual-polarization mini-radars (two fixed and one mobile), described in the following section, were deployed around the Bic basin at $20-30 \mathrm{~km}$ apart from each other, while the reference XPol radar was deployed in the middle of the mini-radar network, which is at the outskirts of the capital city of Chisinau, as shown in Fig. 1. The XPol radar is a high-quality and mobile dual-polarization and Doppler X-band radar that has participated in several international field experiments (Anagnostou et al., 2004, 2009, 2012). In addition to the radars, within the basin, we deployed in situ hydrological and meteorological stations. Specifically, the in situ sensors consist of six raingauge pairs, one two-dimensional video disdrometer, one Doppler flow meter and a stream gauge. In Fig. 2 pictures of XPol and of the deployed disdrometer and raingauges at Chisinau site are shown.

The MOF experimental period captured few rain events that did not exhibit high rain intensities. Autumn 2011 was unusually (according to local climatic records) dry in the Romania-Moldova region. For the quantitative analysis of this study we selected two distinct rain events. The first was

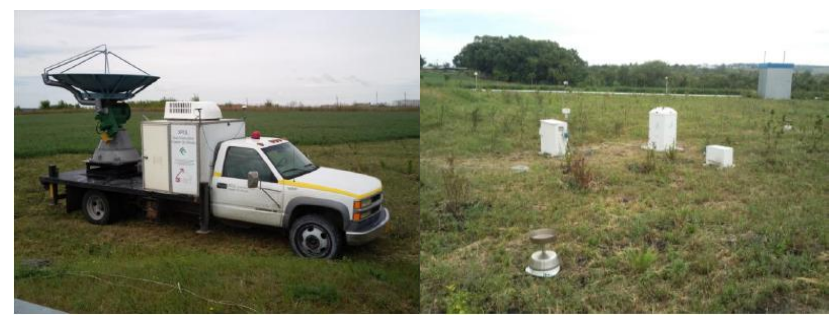

Fig. 2. Pictures of deployed instruments during the Moldova field experiment: XPol radar (left panel) disdrometer and raingauges (right panel) located at Chisinau site.

a convective type storm with small isolated strong rain cells that persisted for $24 \mathrm{~h}$ between 8 and 9 September. The second was a stratiform rain type with widespread moderate rain of longer duration $(36 \mathrm{~h})$ that took place on 8-9 October. Both events were well monitored from all deployed radars and meteorological instruments and their analyses using the HYDRORAD integrated system is discussed in the next sections.

\section{HYDRORAD X-band polarimetric mini-radar system}

The primary goal of HYDRORAD was to optimise a low cost, but robust, dual-polarization $\mathrm{X}$-band radar to provide quantitative precipitation estimates with relatively high spatial and temporal resolution with limited range coverage equivalent to urban areas, small scale catchment basins or extended agricultural domains. To achieve this goal the realisation of the main subsystem of the new mini-radar system was carried out during the project lifecycle. The interfaces of the mini-radar were carefully analysed according to the needs of HYDRORAD project, taking into account some critical parts and carrying out proper design, specification and fabrication of the main subsystems (antenna, radome, transceiver, the control and signal processor and so on). Each component has been fully tested before final system assembly for the production and factory test.

Three mini-radar radar systems were fully tested during MOF campaign. One of the mini-radar (located at Baltata site) was a towed-mobile radar, making possible to deploy the radar in different locations and, thus, optimizing the radar coverage according to any possible future need. The other two radar systems (located at Straseni and Horesti sites) were fixed tower-based radar units. The main characteristics of both fixed and mobile mini-radar units are shown in Table 1 and compared with those of the XPol.

After deployment and set-up activities, the three radars were left in continuous operational mode to acquire volumetric scans at 5 min repetition. Mini-radars scanned in a $360^{\circ}$ sector and for $0.5^{\circ}, 1.5^{\circ}, 2.5^{\circ}$ and $3.5^{\circ}$ elevation sweeps. The two upper elevation sweeps were selected to avoid ground 
Table 1. HYDRORAD mini-radar and XPol operational characteristics.

\begin{tabular}{lrr}
\hline & Mini-radar & XPol \\
\hline Frequency & $9.41 \mathrm{GHz}$ & $9.37 \mathrm{GHz}$ \\
Antenna Gain & $35 \mathrm{~dB}$ & $40 \mathrm{~dB}$ \\
Antenna Type & Offset Cassegrain & Parabolic \\
Maximum Range & $120 \mathrm{~km}$ & $120 \mathrm{~km}$ \\
Beamwidth & $3.0^{\circ}$ & $0.9^{\circ}$ \\
Peak Power & $25 \mathrm{~kW}$ & $60 \mathrm{~kW}$ \\
Radome & $\mathrm{YES}$ & $\mathrm{NO}$ \\
Dual Polarization & $\mathrm{YES}$ & $\mathrm{YES}$ \\
Measurables & $Z Z_{\mathrm{DR}} V, \Phi_{\mathrm{DP}} \rho_{\mathrm{HV}} Z Z_{\mathrm{DR}} V, \Phi_{\mathrm{DP}} \rho_{\mathrm{HV}}$ \\
\hline
\end{tabular}

clutter and beam blockage in some sectors. The pulse repetition frequency was $500 \mathrm{~Hz}$ with $250 \mathrm{~m}$ range resolution. Antenna rotation rate was $20\left({ }^{\circ} \mathrm{s}^{-1}\right)$ and the time period for a full volume scan was about $3 \mathrm{~min}$. The maximum range was set to $60 \mathrm{~km}$ as a conservative choice although maximum range is $120 \mathrm{~km}$. Radar observations included the horizontal reflectivity $Z_{\mathrm{hh}}$, the differential reflectivity $Z_{\mathrm{dr}}$, co-polar correlation coefficient $\rho_{\mathrm{hv}}$ and the differential phase shift $\Phi_{\mathrm{dp}}$. The specific differential phase shift $K_{\mathrm{dp}}$ is estimated as half the gradient of $\Phi_{\mathrm{dp}}$ along the radar ray. The three mini-radar systems worked properly most of the time during MOF campaign and the rainy events were well monitored from all three deployed mini-radars, although some minor system bugs and logistics constraints were found and promptly solved. Polarimetric data assessment was carried out using the softwarebased radar product tool, described in the next section.

Pictures of fixed and mobile mini-radars together with an example of data acquired during MOF campaign are shown in Fig. 3.

\section{HYDRORAD radar-based product generator}

The capability to invert the X-band polarimetric radar measurements into useful hydro-meteorological products is crucial for the full exploitation of the mini radar system developed within HYDRORAD, and to ingest data from any other radar system. Various operational aspects had to be examined to extract quantitative information from radar data and to provide reliable products. In particular, hydrometeor classification, path-attenuation correction, vertical profile correction, rain-rate estimation and nowcasting deserve special attention being the core of any hydro-meteorological application. The overall X-band radar algorithm, called HydroAlg tool, includes

a. a technique for attenuation correction. At X-band frequencies attenuation of radar signal by rain can be quite significant with values greater than $10 \mathrm{~dB}$ in heavy rain. There are many dual-polarization rain attenuation correction algorithms like the ZPHI algorithm (Testud et al., 2000), which is based on $\Phi_{\mathrm{dp}}$ measurements, and
Table 2. Hydrometeor class indexes and corresponding microphysical description, used by the HYDRORAD classification algorithm.

\begin{tabular}{lll}
\hline Index & Acronym & Description \\
\hline 1 & LD & Large Drops \\
2 & LR & Light Rain \\
3 & MR & Medium Rain \\
4 & HR & Heavy Rain \\
5 & H & Hail \\
6 & G/SH & Graupel/ Small Hail \\
7 & DS & Dry Snow \\
8 & WS & Wet Snow \\
9 & IC & Ice Crystal \\
10 & DR & Drizzle Rain \\
11 & WH & Wet Hail \\
12 & WH/R & Wet Hail/Rain \\
\hline
\end{tabular}

its extension with the additions of a $\Phi_{\mathrm{dp}}-Z_{\mathrm{dr}}$ constraint (Bringi et al., 2001). In this study a new attenuation correction algorithm was used which is based on the new rain microphysics parameterizations algorithm (called SCOP-ME) described in Kalogiros et al. (2012a) and Anagnostou et al. (2012) with minimum parameterization error (up to $5 \%$ ). This attenuation correction algorithm is described in detail and compared with other algorithms (Kalogiros et al., 2012b). The new parameterizations use the theoretical Rayleigh scattering limits corrected by a multiplicative rational polynomial function of reflectivity-weighted raindrop diameter to approximate the Mie character of scattering;

b. a technique for hydrometeor classification aimed at partitioning a radar volume in terms of microphysical hydrometeor types. The algorithm provides 12 hydrometeor class index (see Table 2) for each radar range bin using a Bayesian decision rule starting from radar observables and temperature information (Marzano et al., 2008). The hydrometeor classification technique is trained with a radar backscattering-model simulation, based on the $T$ matrix code where liquid, ice and mixed phase hydrometeors are simulated;

c. a technique for VPR (vertical profile reflectivity) correction, based on the melting layer identification, VPR normalisation per sweep, extrapolation and final correction. The method used to correct for the BB (bright band) and mixed phase precipitation effect uses the polarimetric information (i.e., $\rho_{\mathrm{hv}}$ ) to identify the properties of the melting layer (Anagnostou et al., 2009). After detection a correction algorithm for the average apparent vertical profile of reflectivity in each PPI sweep is applied (Kalogiros et al., 2012c);

d. a new polarimetric rainfall estimation. Rainfall estimates based on classical weather radar observations 

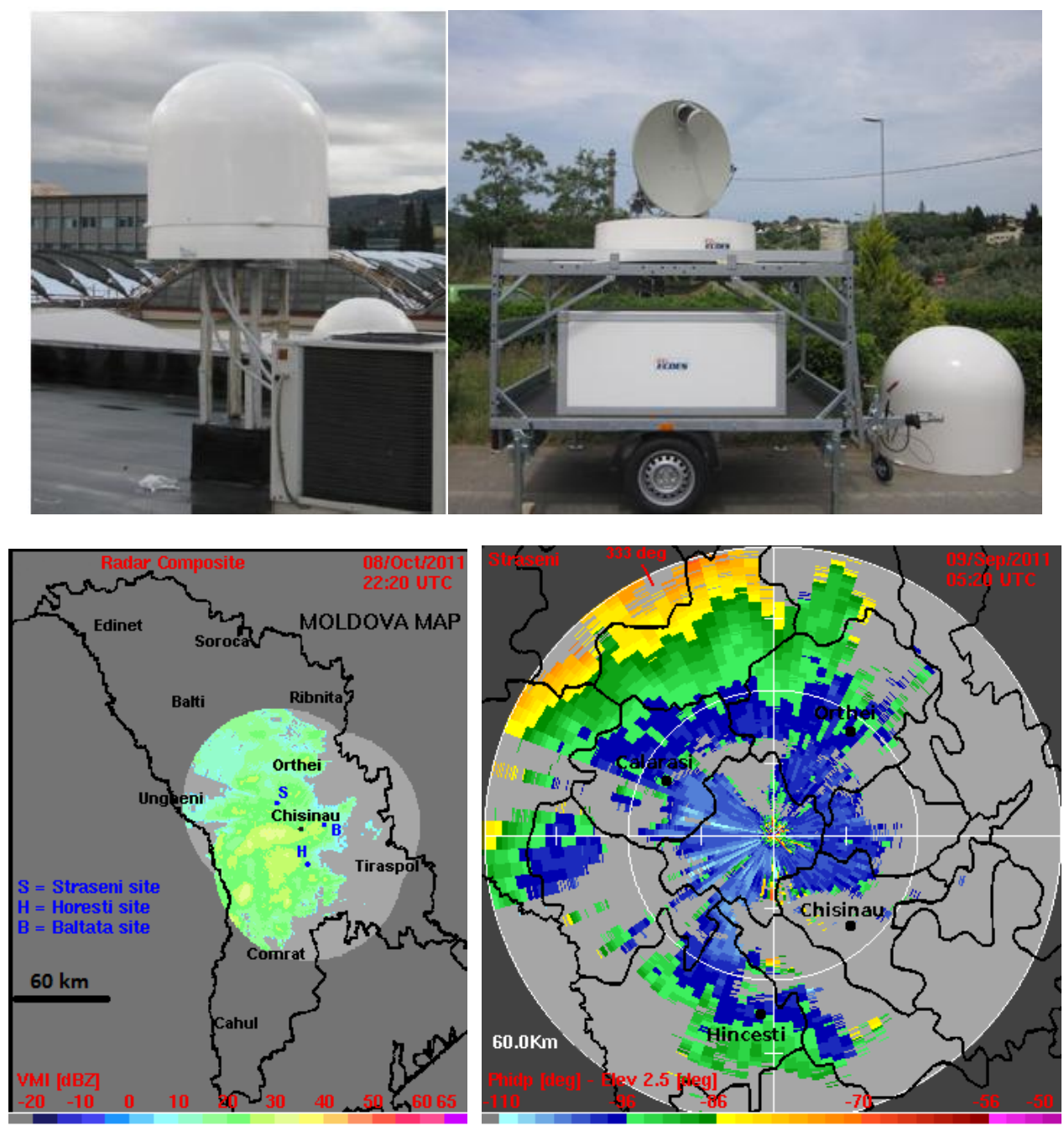

Fig. 3. Pictures of fixed (top left panel) and mobile (top right panel) mini-radars, a sample reflectivity map composite from the three miniradar sites (bottom left panel) and a differential propagation phase shift map (bottom right panel), taken from the Straseni radar site at $60 \mathrm{~km}$ range on 9 September 2011.

have quantitative limitations mainly due to the lack of uniqueness in the relationship of the single radar measurable (reflectivity) to the associated rainfall intensity. The polarization diversity capability of modern weather radars is expected to moderate this effect using polarimetric relations for estimation of the rainfall rate, which combine $Z_{\mathrm{hh}}, Z_{\mathrm{dr}}$ and $K_{\mathrm{dp}}$ (Matrosov et al., 2002; Anagnostou et al., 2004; Park et al., 2005). In this study three rainfall estimators were evaluated.

The first one is a classic $Z-R$ rainfall estimator with fixed coefficients:

$R=3.36 \times 10^{-2} Z_{\mathrm{hh}}^{0.58}$,

where $R$ is rainfall rate in $\mathrm{mm} \mathrm{h}^{-1}$ units and $Z_{\mathrm{hh}}$ is in linear units $\mathrm{mm}^{6} \mathrm{~m}^{-3}$ instead of $\mathrm{dBZ}$. The coefficients in this equation were evaluated from historic
(2005-2006) XPol data in the area of Athens, Greece, and mostly for stratiform rain. However, the coefficients of $Z-R$ estimators are known to vary with geographical area and type of rain. A more efficient form of this equation replaces the fixed coefficients with variable coefficients that depend on polarimetric measurements like Eq. (2) below, which introduces the normalisation of rainfall rate $R$ and reflectivity $Z_{\mathrm{hh}}$ with the intercept parameter $N_{w}$ (units $\mathrm{mm}^{-1} \mathrm{~m}^{-3}$ ) of droplet size distribution (DSD), which is approximated with a normalised Gamma distribution (Bringi and Chandrasekar, 2001). $N_{w}$ is obtained from polarimetric relations found from scattering simulations (Park et al., 2005; Kalogiros et al., 2012a). This polarimetric rainfall estimator with coefficients determined form scattering simulations is

$R_{p 1}=1.305 \times 10^{-3} N_{w}\left(Z_{\mathrm{hh}} / N_{w}\right)^{0.58}$. 
The third rainfall estimator is a new polarimetric estimator which minimises the approximation error using the theoretical Rayleigh scattering limit with the addition of a rational polynomial function of reflectivity-weighted droplet diameter to approximate the Mie character of scattering (Kalogiros et al., 2012a; Anagnostou et al., 2012):

$R_{p 2}=0.8106 F_{R}(\mu) N_{w} D_{0}^{4.67} f_{R}\left(D_{0}\right)$.

$D_{0}$ and $\mu$ are the median volume diameter and the shape parameter of the DSD, respectively, $F_{R}$ is a function of $\mu$, which is included in the Gamma approximation of the DSD, and $f_{R}$ is a third degree rational polynomial of $D_{0}$ with constants evaluated by the simulations;

e. a short-term nowcasting techniques able to identify and forecast convective cells. The basic principle of Spectral Pyramidal Advection Radar Estimator (SPARE) is to perform spatial correlation on filtered radar images in the spectral domain and, by means of the estimated displacement vectors, to define how different rainy structures move. The procedures take a temporal sequence of available radar maps and propagate the last available one in the future (Montopoli et al., 2010).

The HydroAlg was applied on the mini-radar observations during the MOF campaign as well as the XPol radar data. From the analysis of both dual-polarized amplitude and phase return, described in the next sub-section, we can assess that polarimetric mini-radars exhibit the expected performances in terms of capturing the vertical and horizontal distribution of stratiform and convective precipitation with features that are consistent with the ones derived from the high-power and high-resolution XPol radar, taken as a benchmark. For the distinction between stratiform and convective precipitation from the radar-observation point of view, it is well known that the existence of a bright band is connected to stratiform rain, whereas a fairly uniform vertical profile of reflectivity is typical of convective rain (Steiner et al., 1995). This distinction is also carried out for raingauges on the basis of rain-rate temporal evolution (corresponding to spatial distribution in case of radars). As a matter of fact, stratiform rain events are characterised by slow variations of the precipitation system, whereas convection rain is characterised by a significant variability in time and space.

Initial results of the HydroAlg processing chain, derived from MOF data, are described in the following sub-sections.

\subsection{Hydroalg attenuation correction}

The rain attenuation correction algorithm was applied to the mini-radars and the XPol radar for all the collected data during MOF. Figure 4 shows an example map of horizontal reflectivity $\mathrm{Z}_{\mathrm{hh}}$ from PPI scans of XPol and R3 (Horesti) mini-radar at about the same time during the rain event of
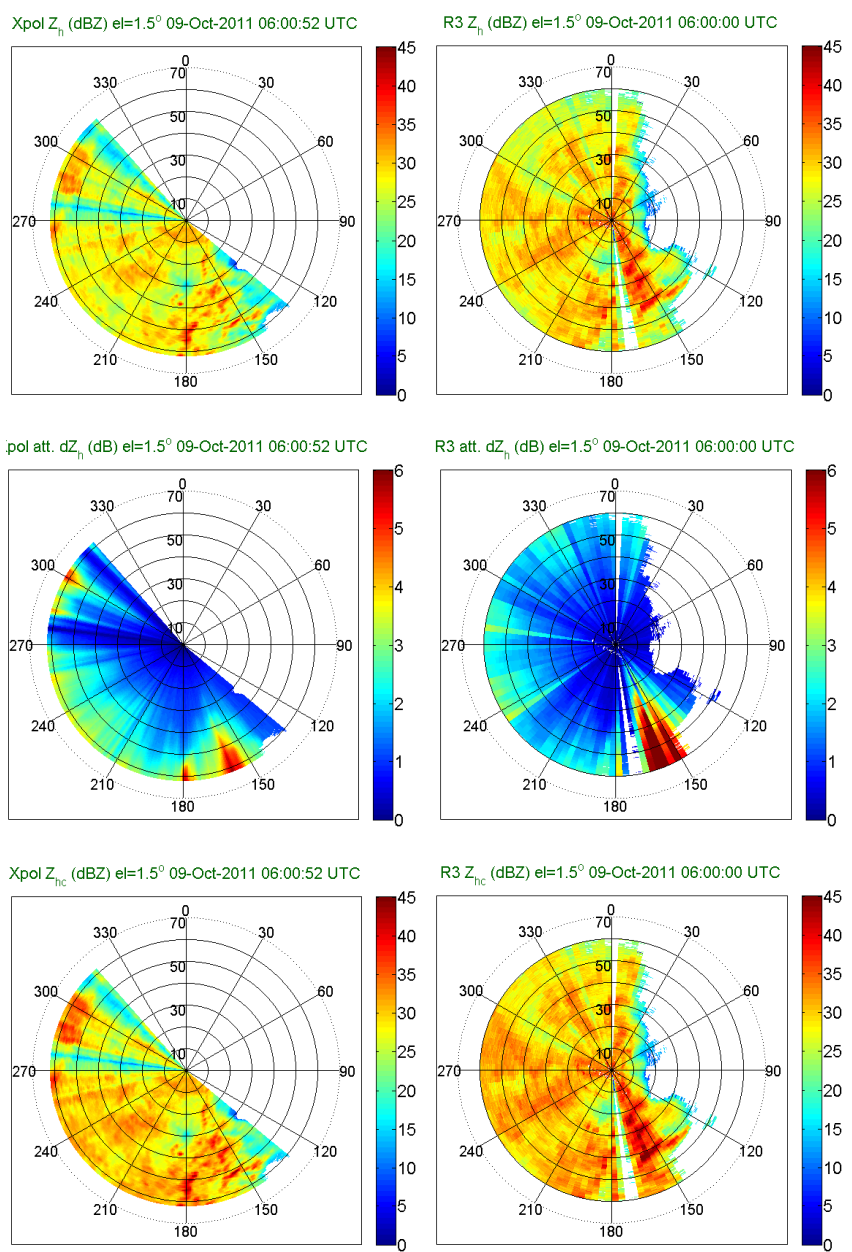

Fig. 4. Sample PPI maps at $0.5^{\circ}$ elevation angle of rain-path attenuation correction using XPol (left column) and R3 mini-radar (right column) for the rain event on 9 October 2011. PPIs refer to horizontally-polarized reflectivity $Z_{\mathrm{hh}}$, estimated specific attenuation $d Z_{\mathrm{hh}}$ and corrected reflectivity $Z_{\mathrm{hc}}$.

8-9 October 2011 when widespread rain occurred in the experimental area.

The specific-attenuation correction due to rain is indicated by $d Z_{\mathrm{h}}$ parameter and $Z_{\mathrm{hc}}$ is the path-attenuation corrected reflectivity. Range is given in $\mathrm{km}$ and azimuth angles relative to north is in degrees. The mini-radars had azimuth sectors of partial beam blockage due to terrain as evident, for example, for $\mathrm{R} 3$ at about $170^{\circ}$. The attenuation correction reaches up to $6 \mathrm{~dB}$ which is a moderate, but significant value due to the low reflectivities (up to $45 \mathrm{dBZ}$ ) which are usually observed in widespread rain. A fairly good consistency between XPol and mini-radar attenuation estimates is also noted.

\subsection{HydroAlg hydrometeor classification}

The radar-based hydrometeor classification results are discussed in this section, assuming that the path-attenuation 

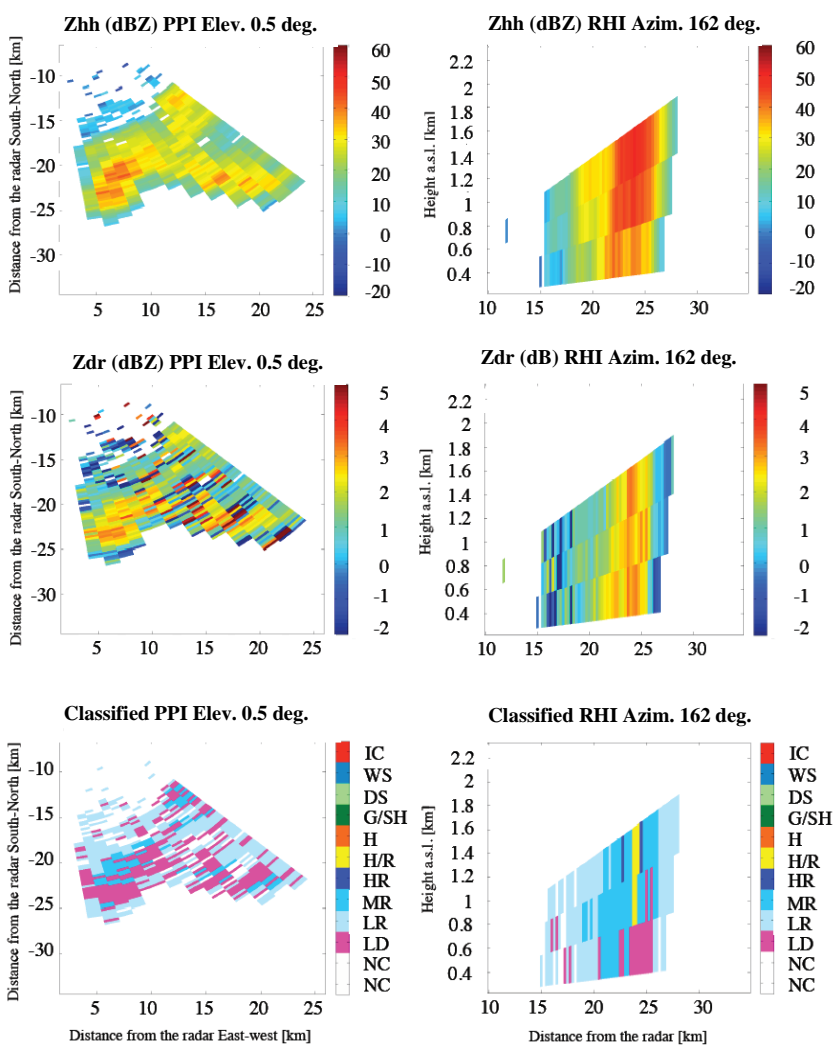

Fig. 5. Example of a rain cell as seen from Horesti radar installation on 9 September 2011 at 12:55 UTC in terms of $Z_{\mathrm{hh}}, Z_{\mathrm{dr}}$ and the classified products for PPI horizontal maps at $0.5^{\circ}$ (left column) and RHI vertical sections (right panel).

correction is already successfully applied as shown in Sect. 4.1. The approach is based on the comparison between the expected microphysical results with those obtained from measurements within the MOF campaign. Figure 5 shows qualitative examples of the classification procedure and its inputs, $Z_{\mathrm{hh}}$ and $Z_{\mathrm{dr}}$ in terms of horizontal and vertical sections (also called respectively Plan Position Indicator, PPI and Range Height Indicator, RHI). A zoomed view has been chosen to better highlight regions where rain cells occurred. One case at 12:55 UTC on 9 September 2011 is shown. This example shows that $Z_{\mathrm{hh}}$ has a good texture and selfconsistency with a spatial structure typical of rain cells. $Z_{\mathrm{dr}}$ seems to be less homogeneous than $Z_{\mathrm{hh}}$ showing regions of high spatial variability with a large dynamics (i.e. $Z_{\mathrm{dr}}$ passes from low to high values pixel by pixel). This mainly affects the classification procedure which assigns a not classified (NC) label to some pixels. As argued in Marzano et al. (2008), if the minimum Bayesian distance is larger than a decision threshold, the corresponding radar bin is labeled as "not classified" (NC). The decision threshold is usually determined in an empirical way. A case when this condition may happen is relative to non-hydrometeor targets such as birds and residual ground clutter.

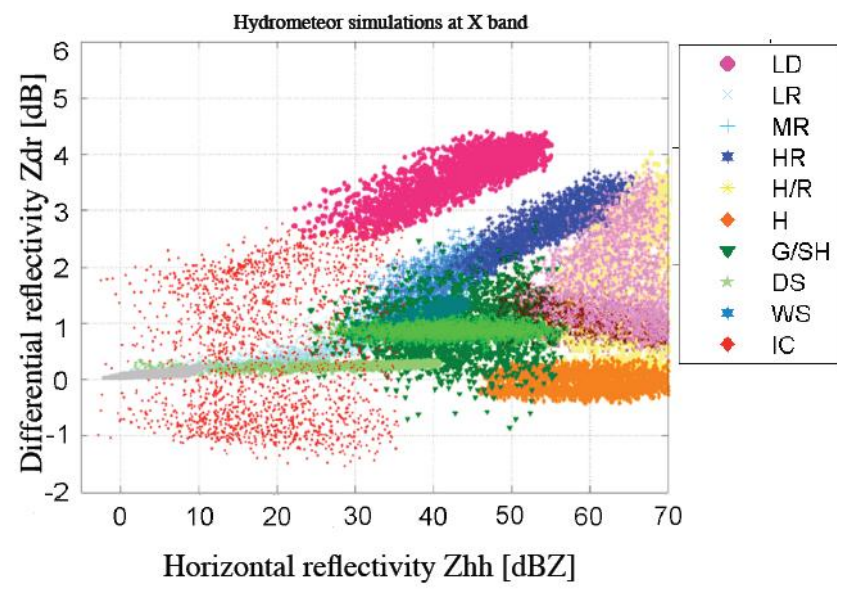

Fig. 6. Scatterplot between $Z_{\mathrm{hh}}$ and $Z_{\mathrm{dr}}$ derived from numerical simulations at $\mathrm{X}$ band. The scatterplot is segmented as a function of hydrometeor classes that are colour coded.

An evidence of what just stated is shown by the horizontal section of Fig. 5 where portions of the identified rain cell remain unclassified (blank), even though $Z_{\mathrm{hh}}$ and $Z_{\mathrm{dr}}$ are not labelled as missing data. On the other hand, the vertical sections of the same figures are quite interesting since they reveal a vertical rain cell structure where hail/rain mixture at the top of the rain cell becomes large drop class, mixed to medium-rain class close to the ground. This is also plausible behaviour for a rain cell vertical structure.

Indeed, validation of a hydrometeor classification scheme is tough task which would require survey within the rain cloud itself. Synthetic radar observations can be obtained using a radar backscattering simulator able to reproduce the characteristic features of a radar system in terms of its observables (e.g. $Z_{\mathrm{hh}}, Z_{\mathrm{dr}}, K_{\mathrm{dp}}$ ) at $\mathrm{X}$ band (Marzano et al., 2010). From the mini-radar observables the classification scheme can be applied again and compared again with the synthetic outputs. Figures 6 and 7 show a comparison between the expected correlation of the radar simulations for each hydrometeor category (shown in Fig. 6) and the actual radar products, derived from data acquired by mini-radars during the MOF campaign (shown in Fig. 7). Note that the whole radar volume of $Z_{\mathrm{hh}}$ and $Z_{\mathrm{dr}}$ for each rain event and all hydrometeor classes have been considered.

The analysis of Figs. 6 and 7 shows that the collected events do not include all the hydrometeor classes; interestingly, both DS and G/SH classes exhibit a good match between synthetic and actual measurements. Eventually the high degree of overlapping of some classes (e.g. LD and HR) in Fig. 7, with respect to what is expected, is an undesired outcome, probably due to some residual noise in the measurements, especially for $Z_{\mathrm{dr}}$. Some techniques to reduce this effect are currently under evaluation. 


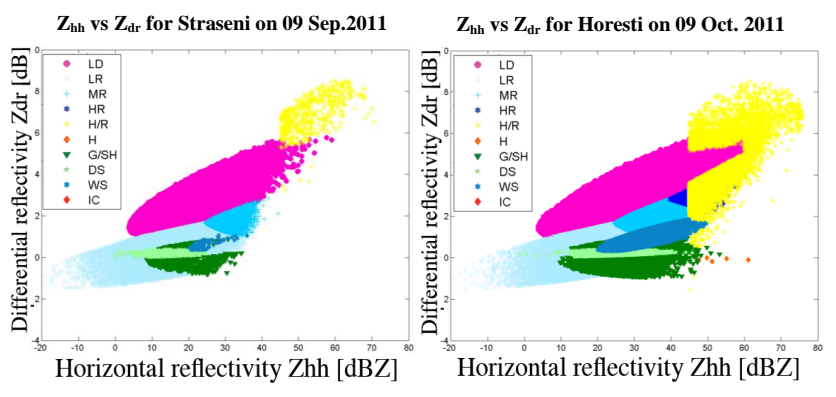

Fig. 7. As in Fig. 6, but using the HydroAlg classification technique applied to mini-radar volume acquisitions during MOF rain events on 9 September and 9 October 2011 for Straseni and Horesti sites.
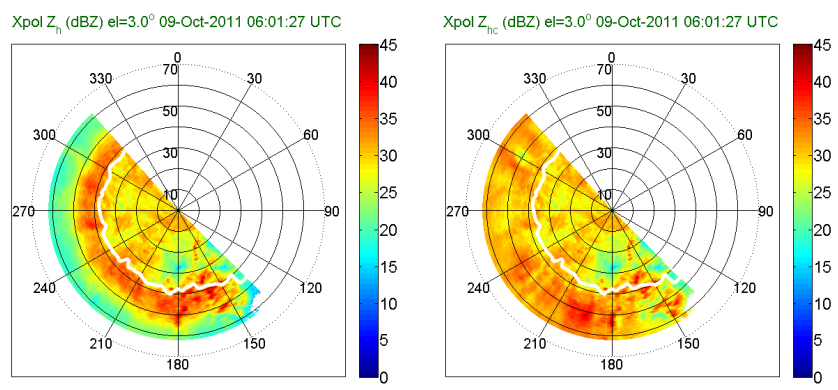

Fig. 8. Example of VPR correction of XPol PPI scan at an antenna elevation of $3.0^{\circ}$ during the rain event on 9 October 2011, showing the bright band due to the melting layer.

\subsection{HydroAlg VPR correction}

Due to the use of high elevation angles of the radar antennas to avoid beam blockage by terrain features, melting layer effects (i.e. bright band) were observed at these elevation angles during widespread (stratiform) precipitation. For MOF data a low elevation angle $\left(1.5^{\circ}\right)$ was used for rainfall estimation in order to avoid melting layer effects and to minimise effects due to ground clutter, but, in the next sections we present evaluation of the VPR application in higher elevation sweeps.

Figure 8 presents a high elevation angle at $3^{\circ}$ PPI from $\mathrm{XPol}$ radar. The bright band is seen as a circular zone of high reflectivities values in the range from 40 to $50 \mathrm{~km}$ corresponding to altitudes of about 2000 and $2500 \mathrm{~m}$, respectively. The white line shown is the base of the melting layer which was detected using $\rho_{\mathrm{hv}}$ as the rain-to-mixed phase classification criterion. The reflectivity, corrected for its vertical profile (VPR) error, is indicated with $Z_{\mathrm{hc}}$. It is apparent that the bright band has been removed in the corrected reflectivity.

Because of the wider antenna beam width of the mini$\operatorname{radar}\left(3^{\circ}\right.$ vs. $1^{\circ}$ of XPol) and worst siting in respect to Xpol, it was difficult to detect the bright band at ranges longer than $40 \mathrm{~km}$ (which reflects into a vertical resolution of more than $2000 \mathrm{~m}$ due to the mini-radar beam divergence). For this reason we cannot present the same result of Fig. 8 for the

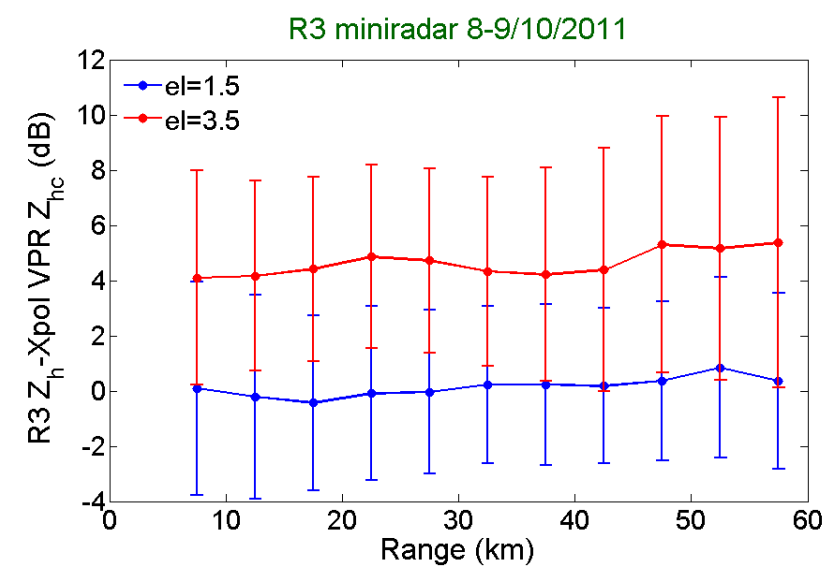

Fig. 9. Statistical difference between R3 mini-radar and XPol measurements versus range during the 8-9 October 2011 rain event for two different antenna elevation angles.

mini-radar. Due to the small number of events available during MOF, it was not possible to build up robust statistics for the mini-radar observations. This VPR aspect needs to be further investigated and will be the subject of future research to find proper algorithms that will mitigate this limit.

Figure 9 shows the difference on reflectivity between the measurements from R3 mini-radar with XPol measurements versus the radar range for all data of the widespread rain event on 8-9 October 2011. Only data with correlation coefficient $\rho_{\mathrm{hv}}$ higher than 0.8 (i.e., good rain signal) were included in the statistical comparison. The reflectivity of miniradars was calibrated against XPol, which had been calibrated against disdrometer data, using their $1.5^{\circ}$ elevation data. Thus, the reflectivities of mini-radars and XPol agree (zero bias) on that elevation. The wide beam results in partial beam blockage by the terrain at elevation angles below $3.5^{\circ}$. On average it has been found that, due to this partial beam blockage, the R3 mini-radar reflectivities at $0.5^{\circ}, 1.5^{\circ}$ and $2.5^{\circ}$ elevations were lower from the reflectivity at $3.5^{\circ}$ elevation angle by $10.5 \mathrm{~dB}, 4 \mathrm{~dB}$ and $1 \mathrm{~dB}$, respectively. These difference values depend also on the orography around the mini-radar because different terrain will cause different partial blockage. The beam blockage and the wide beam seem to have an influence on the differential phase shift and $\rho_{\mathrm{hv}}$ even though the amount of collected data does not allow making an exhaustive analysis at present.

\subsection{HydroAlg rain-rate estimation}

For the radar-based estimation of rainfall rate, the $1.5^{\circ}$ elevation angle was used. Data from two rain events were considered. Figure 10 shows an example of reflectivity maps from R3 mini-radar and XPol during the first rain event (89 September 2011) which was of convective type with isolated strong rain cells. The positions of the three mini-radars and the six raingauge sites, relative to XPol, are also shown in 
XPol $Z_{\mathrm{h}}$ (dBZ) 09-Sep-2011 11:50:00 UTC

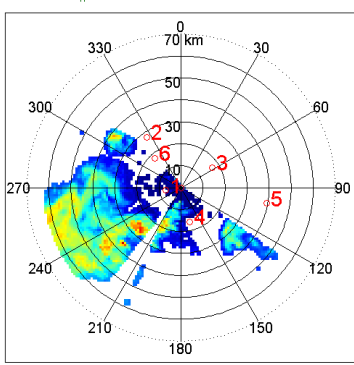

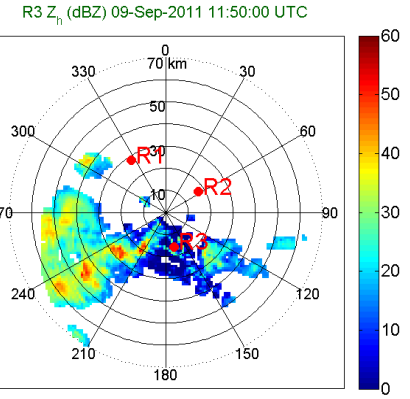

Fig. 10. PPI scans of horizontal reflectivity $Z_{\mathrm{hh}}$ measured from the XPol and the R3 mini-radar at an elevation angle of $1.5^{\circ}$. The locations of the three mini-radars and the six pairs of rain gauges relative to XPol are also shown.
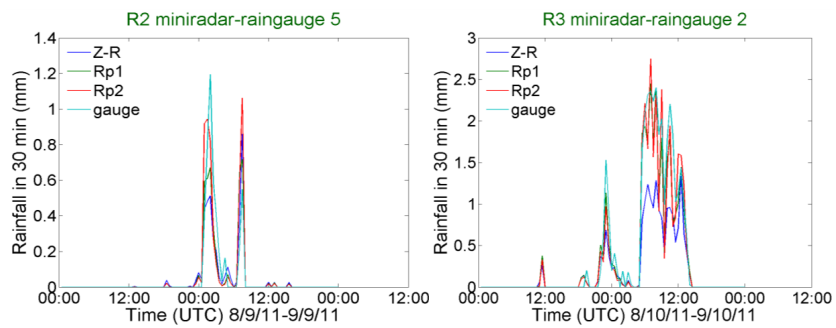

Fig. 11. Time series of mini-radar rainfall estimates (accumulation in $30 \mathrm{~min}$ ) from the three retrieval algorithms, expressed by Eqs. (1)-(3).

the figure. The mini-radar reflectivity field agrees well with the near-concurrent field from XPol, which shows the capability of the mini-radar to capture well the spatial variability of rain. The second rain event (8-9 October 2011) was of stratiform rain type with widespread moderate rain.

Figure 11 presents time series comparison between the mini-radar and XPol rainfall estimates (accumulation in $30 \mathrm{~min}$ ) from the three rainfall algorithms $Z-R, R_{p 1}$ and $R_{p 2}$ and the raingauge measurements. It was not possible to compare the mini-radars to all the raingauges because of partial beam blockage by the terrain in the direction of some raingauges. The time series comparison shows that the rainfall estimates by the mini-radars tend to follow the temporal evolution of rainfall fairly well and that the classical estimator $Z-R$ generally underestimates the rainfall rate. It should be noted that the constants in $Z-R$ relation were estimated from historic XPol data in Athens, Greece.

Histograms of the difference between mini-radar and XPol rainfall estimates are shown in Fig. 12. This comparison was made after interpolation of the rainfall maps for each miniradar and XPol on a common grid of $90 \mathrm{~km}$ radius with $1 \mathrm{~km}$ spatial resolution and XPol position at the center of the grid. The bias of the mini-radar rainfall estimates is small. Tails in the histograms are probably due to altitude differences of the measurement volume of the mini-radars and XPol and
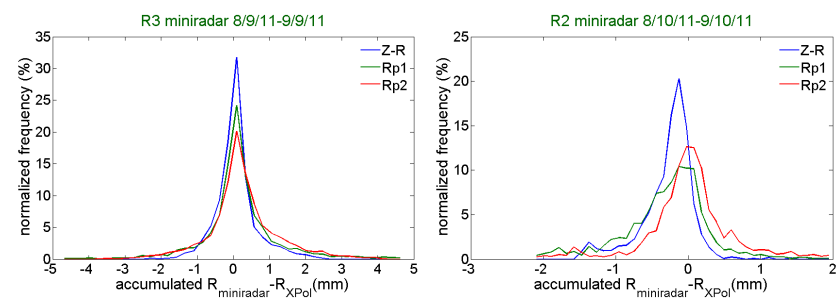

Fig. 12. Histograms of difference between mini-radars ( $R 3$ on the left and R2 on the right) and XPol estimates of total rainfall accumulated using the three retrieval algorithms of Eqs. (1)-(3).
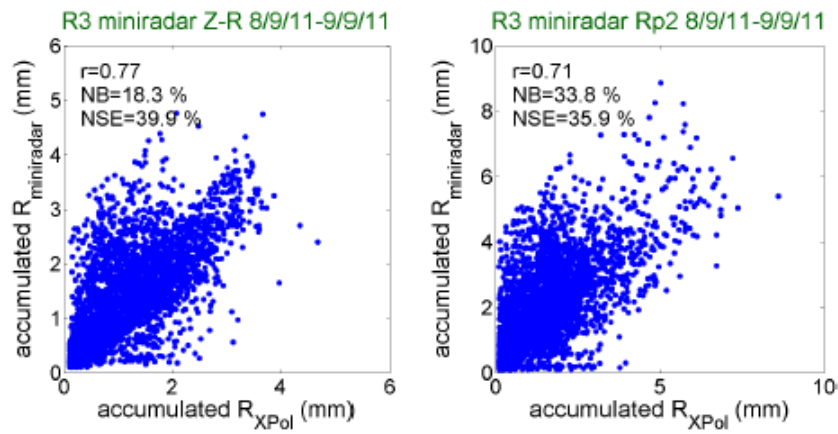

Fig. 13. Scatterplot of accumulated rain from XPol and R3 miniradar, using two different rain estimation algorithms $(Z-R$ on the left panel, Rp2 on the right panel).

beam blockage effects on the radar data by the terrain in some azimuth sectors.

Finally, Fig. 13 shows the comparison of total accumulated rain in the experimental area from XPol and R3 miniradar (classic and $R_{p 2}$ estimators) during the rain event of 8-9 September 2011. The correlation coefficient is $r$, NB is the normalised bias and NSE is the normalised standard error. $\mathrm{R} 3$ rainfall estimates are similar with XPol, but with a small overestimation, which is due to the differences in the time and altitude of the measurement volume of the two radars.

\subsection{HydroAlg nowcasting}

The SPARE nowcasting methodology has been evaluated in terms of score indexes. Widely used statistical skill score indicators such as probability of detection (POD), false alarm rate (FAR) and critical success index (CSI) were used. Their main characteristics are illustrated in Table 3. Error budget of SPARE predictions is evaluated by using the MOF case study dataset. This analysis is carried out to quantify the statistical error between SPARE predictions and radar actual observations. This is an a posteriori error evaluation, which allows to exemplifying the performance of the nowcasting algorithm.

The radar product, used for nowcasting purposes, consists of maximum reflectivity of radar volumes over each pixel (specifically VMI, vertical maximum indicator) from the Straseni, Baltata and Horesti sites. This choice tends to 
Table 3. Main characteristics of score indexes used to evaluate the HYDRORAD nowcasting algorithm.

\begin{tabular}{llll}
\hline Index & Range values & Characteristics & Example \\
\hline POD & $\begin{array}{l}\text { from } 0 \text { to } 1 \\
\text { best values is } 1\end{array}$ & $\begin{array}{l}\text { Sensitive to hits, but ignores false alarms, it is } \\
\text { the fraction of the observed events were cor }- \\
\text { rectly forecast }\end{array}$ & $\begin{array}{l}\text { POD }=0.7 \text { means that } 70 \% \text { of observed pixel } \\
\text { were correctly forecasted. }\end{array}$ \\
FAR & $\begin{array}{l}\text { from } 0 \text { to } 1 \\
\text { best values is } 0\end{array}$ & $\begin{array}{l}\text { Sensitive to false alarms, but ignores misses, it } \\
\text { is the fraction of the predicted events actually } \\
\text { did not occur }\end{array}$ & $\begin{array}{l}\text { FAR }=0.25 \text { means that } 25 \% \text { of forecasted } \\
\text { pixel were not observed }\end{array}$ \\
CSI & $\begin{array}{l}\text { Measures the fraction of observed and/or fore- } \\
\text { from to } 1 \\
\text { best values is } 1\end{array}$ & $\begin{array}{l}\text { CSI }=0.6 \text { means that } 60 \% \text { of forecasted and/or } \\
\text { observed pixel were correctly forecasted }\end{array}$ \\
\hline
\end{tabular}

mitigate the unavoidable clutter contamination and take into account the peak of reflectivity. Environmental clutter is operationally mitigated by our automatic procedures through a proper combination of a Doppler filtering and a spatial texture automatic analysis.

The left panels of Fig. 14 show the average trend of all three score indicators, previously described, as a function of the forecast time. As expected, radar nowcasting skills decrease when forecast time increase; note that slightly worse results have been obtained for the Straseni site mini-radar, probably due to a visibility worse than the other two sites. In any case, the overall results seem shown the effectiveness of the SPARE approach applied to the mini-radar systems once compared with the results available from the open literature.

The right panels of Fig. 14 show comparisons of SPARE against the Eulerian prediction scheme which is often taken as a benchmark. Eulerian persistence considers the last available radar map frozen for the entire prediction period. For conciseness, only results for the CSI are shown, although similar results are found in conjunction with POD and FAR. There is an overall improvement of SPARE against the Eulerian benchmark method for the entire forecast period, in which the average improvement is approximately $12 \%$.

\section{HYDRORAD hydrometeorological forecasting tool}

An integrated tool for short-to-medium-range forecasting using coupled hydrological models, meteorological models and mini-radar data networks has been developed and tested during the MOF campaign. The numerical weather forecasting modelling system was implemented and tuned for Moldovan territory to medium range predictions able to ingest $\mathrm{X}$-band radar high-resolution products and to interface with the hydrological model.

The operational weather forecast was performed using the Mesoscale Model 5 (MM5), a limited area model (LAM), developed by Pennsylvania State University and National Center for Atmospheric Research (PSU/NCAR) (Grell et al., 1994). The main purpose of integrating $X$ band radar data in meteorological modelling is to assess the improvements
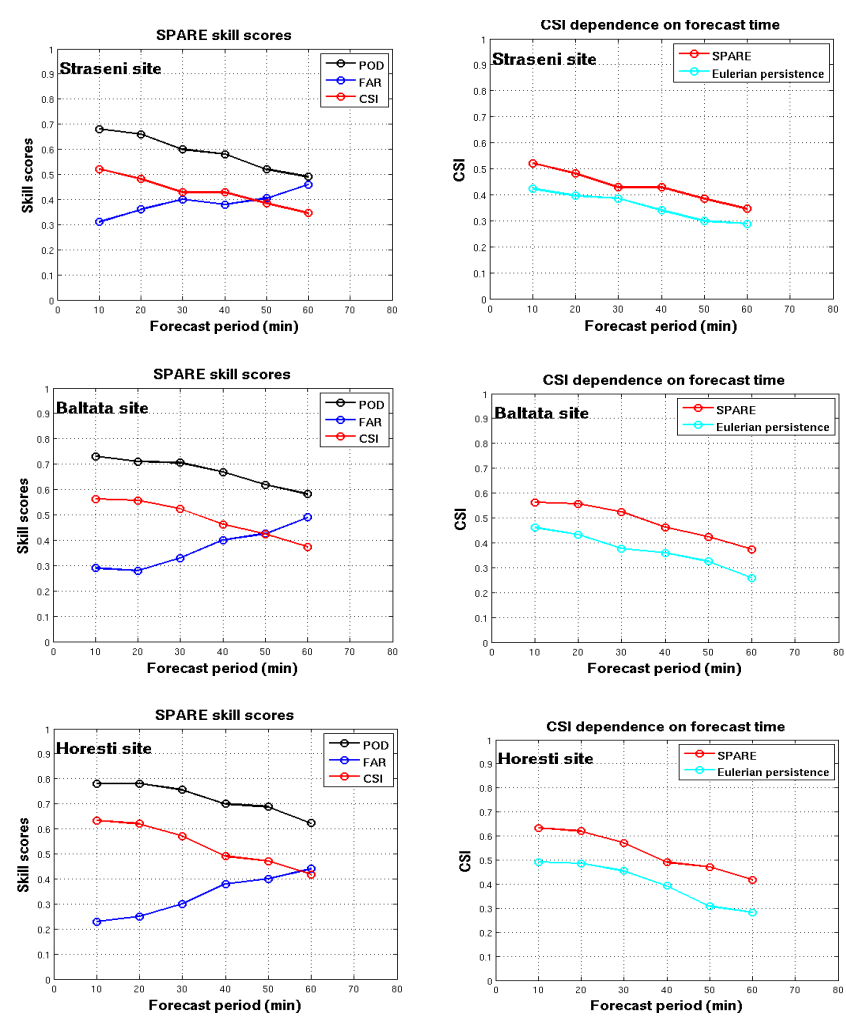

Fig. 14. Left panel: SPARE skill score statistics for test set where lines represent the ensemble mean score values. Right panel: comparison of SPARE with Eulerian persistence for Straseni (top), Baltata (middle) and Horesti (bottom) sites.

that can be obtained in flood risk and flood emergency management using mini-radar network estimate rain. We implemented a new alternative and simpler technique with respect to the three-dimensional variational (3DVAR) and nudging data assimilation (Leuenberger et al., 2007; Rossa et al., 2010), by exploiting the tuning of microphysical parameterization of the operational MM5 version (Gilmore et al., 2004).

Radar data were ingested within the model forecast assessment and the microphysical module optimisation. An example is shown in Fig. 15 where maps of 6 and $24 \mathrm{~h}$ 

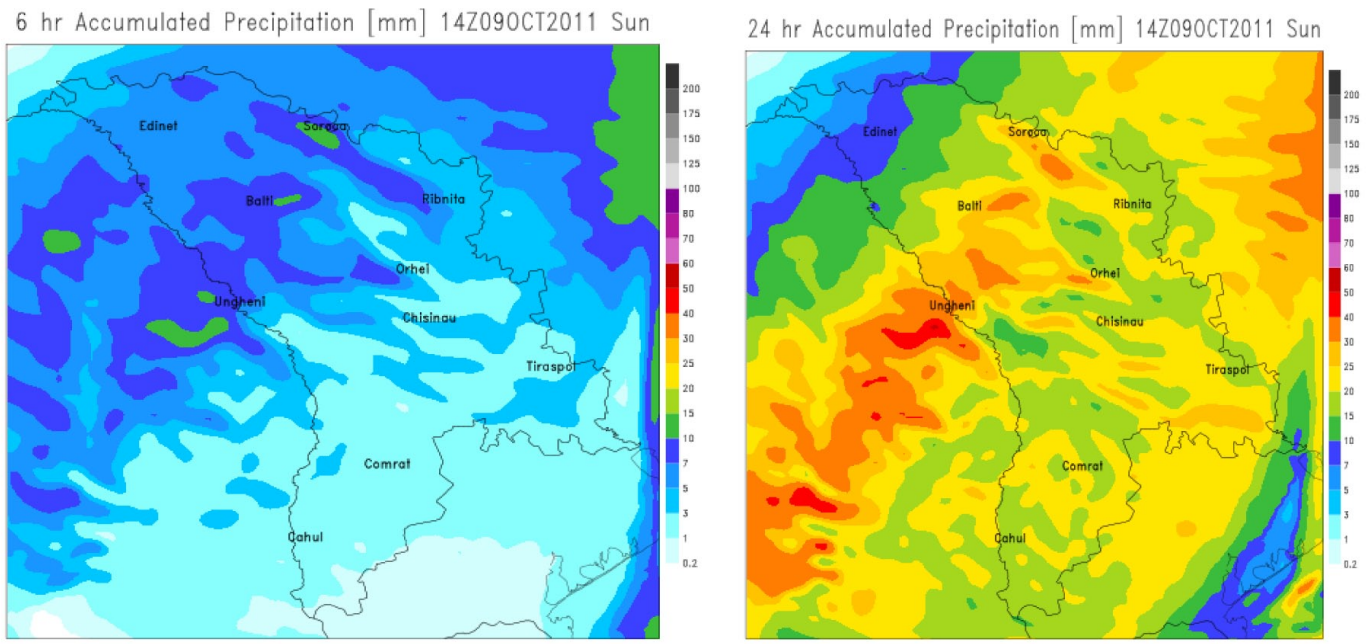

Fig. 15. Accumulated rain (6 and $24 \mathrm{~h})$, forecasted by MM5 weather forecast model over Moldovan territory.
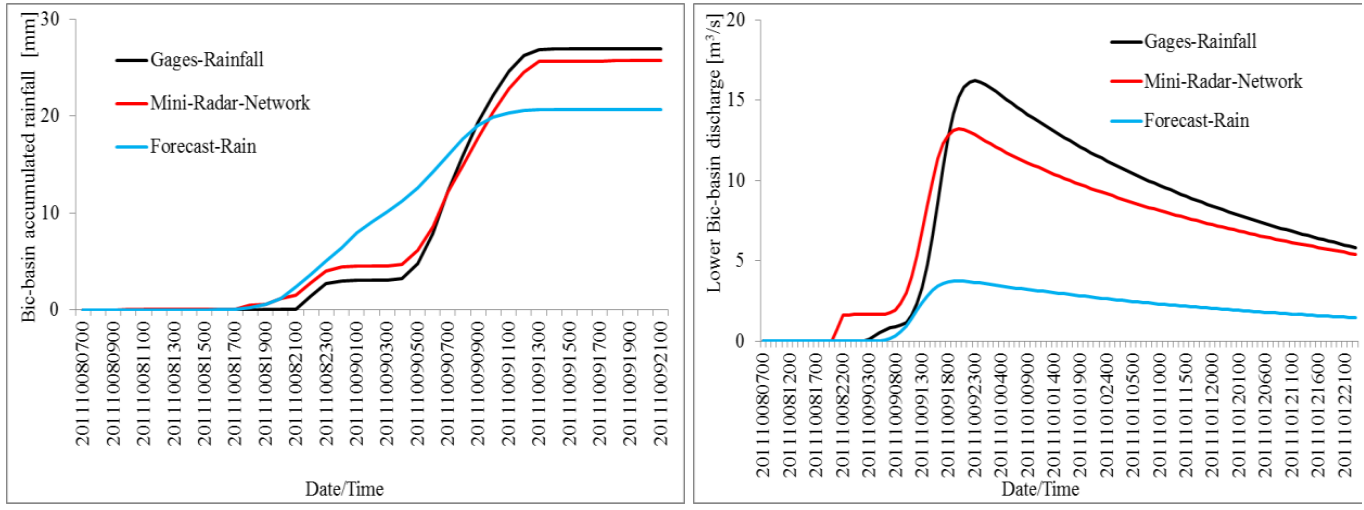

Fig. 16. Time series of Bic basin average rainfall accumulations (left panel), based on raingauge measurements, mini-radar network estimates and MM5 forecasted rainfall; and Bic basin streamflow simulations (right panel), obtained from the hydrologic model forced with the various rainfall data sources.

forecasted rain accumulation by the MM5 model on the whole Moldovan territory are plotted. Verification of the forecasted fields will be presented in the form of basin average rainfall discussed next.

The hydrological model implemented on Moldova region is based on a semi-distributed parametric scheme that includes a hydrologic (HEC-HMS: Hydrologic Engineering Center - Hydrologic Modeling System) and hydraulic (HECRAS: Hydrologic Engineering Center - River Analysis System) modelling chain (e.g. USACE, 2010). Both models were set up using historical data from Bic basin in Moldova about geology, land surface characteristic (terrain, soil, vegetation) and atmospheric forcing (radar, model and in situ data). A main goal of river management is the prevention of damage from flooding. This can be carried out by means of integration of the hydrologic model of the basin with the (i) mini-radar network rain estimated and (ii) numerical weather prediction model forecasted rainfall data as well as meteorological data from the area aimed to predict the timing and magnitude of flooding, which consequently can be a key tool in flood management. The main purpose of integrating mini radar data in hydrologic modelling is to assess the improvements that can be obtained in flood risk and flood emergency management using mini-radar network rain capable of reducing the uncertainty relative to sparse network of raingauges.

The developed hydro-meteorological forecast system was tested during MOF. Figure 16 shows time series of Bic basin-average rainfall accumulations by gauges, the miniradar network observations and MM5 analysis and corresponding streamflow simulations obtained from the hydrologic model forced with the three rainfall datasets. Basinaverage rainfall was determined using interpolation for the rain gauge measurements, and arithmetic averaging for the 
gridded precipitation fields from the mini-radar network and MM5. As shown in Fig. 16 (left), the general result from the presented rainfall time series is a moderate underestimation $(20 \%)$ and weaker temporal variability of basin average rainfall by the MM5 forecasts relative to gauges, which is expected when it comes to quantitative precipitation forecasting of frontal systems. On the other hand, the quantitative precipitation estimation by the mini-radar network observations exhibits close agreement with the gauge basin-average rainfall exhibiting an underestimation of about $8 \%$. The flow predictions based on the various rainfall inputs are shown in Fig. 16 (right). A point to note is that the low basin average rainfall bias is magnified through runoff simulations. The MM5 bias exhibits the most significant error propagation with respect to the mini-radar network rainfall based runoff simulations. This enhancement in underestimation is due to the dry initial basin conditions that resulted in a nonlinear propagation of the basin response error from rainfall. Overall, preliminary results from this storm analysis show that the mini-radar network can provide high-quality rain fields, which can support hydrological modelling within poorly instrumented geographical regions.

\section{Concluding remarks}

This paper presented the results of HYDRORAD project, which objective was the development of an innovative integrated system, consisting of networks of small-size/low power dual-polarization X-band radars and an advanced system of radar retrieval algorithms and software-based tools for hydro-meteorological monitoring and nowcasting. The core of the integrated system is the X-band polarimetric mini-radars. A preliminary comparison of observations from the polarimetric mini-radars against a benchmark polarimetric X-band radar showed promising results. The mini-radars were shown to measure accurately the spatial variability of rain, but they exhibit some problems with partial beam blockage and significant vertical averaging especially at long ranges due to their wider beam relative to the larger antenasize XPol.

New polarimetric algorithms for hydrometeor classification, VPR and attenuation correction, rainfall estimation and nowcasting, and a hydro-meteorological modelling system were applied satisfactorily on the mini-radar network observations and tested based on data from a two-month field campaign in Moldova. Despite the lower performance at longer ranges $(>40 \mathrm{~km})$ with respect to XPol radar rainfall estimates the mini radars are shown to provide a reliable low-cost solution for weather and flood monitoring at local scale. Networks of mini-radars can cover broader areas particularly in complex terrain where operational systems exhibit observational gaps. Introducing high-resolution rainfall estimates from the mini-radar network into meteorological and hydrological models constitutes a challenge that can potentially improve hydro-meteorological forecasting. Such a tool is not currently readily available in the weather radar industry.

Future research will be devoted to extend the herein project with additional field observations as part of our continuing effort to improve the HYDRORAD radar system and hydro-meteorological integration framework. Data collected from currently on-going field experiments will support the further development of our algorithms and the robust verification of their accuracy and consistency in terms of rainfall estimations and hydro-meteorological forecasting.

Acknowledgements. This research has received a financial support from the European Union's Seventh Framework Programme (FP7/2007-2013) under grant agreement n 232156 within FP7SME-2008-1. The authors acknowledge the European Commission Project Officers for their helpful suggestions during the course of the HYDRORAD project.

We also thank the three reviewers for their helpful comments and suggestions which have prompted us to improve the manuscript readibility and its effectiveness.

Edited by: A. Mugnai

Reviewed by: F. Russo, E. A. S. Smith, and one anonymous referee

\section{References}

Anagnostou, E. N., Krajewski, W. F., and Smith, J.: Uncertainty Quantification of Mean-Field Radar-Rainfall Estimates, J. Atmos. Ocean. Technol., 16, 206-215, 1999.

Anagnostou, E. N., Anagnostou, M., Krajewski, W., Kruger, A., and Miriovsky, B.: High-resolution rainfall estimation from X-Band polarimetric radar measurements, J. Hydrometeor., 5, 110-128, 2004.

Anagnostou, E. N., Grecu, M., and Anagnostou, M. N.: X-band polarimetric radar rainfall measurements in keys area microphysical project, J. Atmos. Sci., 63, 187-203, 2005.

Anagnostou, M. N., Anagnostou, E. N., and Vivekanandan, J.: Correction for Rain Path Specific and Differential Attenuation of XBand Dual-Polarization Observations, IEEE Trans. Geosci. Rem. Sens., 44, 2470-2480, 2006.

Anagnostou M. N., Kalogiros, J., Anagnostou, E. N., and Papadopoulos, A.: Experimental results on rainfall estimation in complex terrain with a mobile X-band polarimetric radar, Atmos. Res., 94, 579-595, 2009.

Anagnostou, M. N., Kalogiros, J., Marzano, F. S., Anagnostou, E. N., Montopoli, M., and Picciotti, E.: Performance evaluation of a new rain microphysics algorithm for dual-polarization X-band radars using long-term radar and disdrometer measurements, J. Hydrometeor., doi:10.1175/JHM-D-12-057.1, online first, 2012.

Bringi, V. and Chandrasekar, V.: Polarimetric Doppler weather radar, Cambridge University Press, Cambridge, UK, 2001.

Bringi, V., Keenan, T., and Chandrasekar, V.: Correcting C-band radar reflectivity and differential reflectivity data for rain attenuation: a self consistent method with constraints, IEEE Trans. Geosci. Remote Sens., 39, 1906-1915, 2001.

Gilmore, M. S., Straka, J. M., and Rasmussen, E. N.: Precipitation uncertainty due to variations in precipitation particle parameters 
within a simple microphysics scheme, Mon. Weather Rev., 132, 2610-2627, 2004.

Grell, G., Dudhia, S., and Stauffer, D. R.: A description of the fifth generation of Penn State/NCAR mesoscale model (MM5), NCAR/TN-398+STR, Natl. Cent. For Atmos. Res., Boulder, Colourado, 1994.

Hossain, F., Anagnostou, E. N., Dinku, T., and Borga, M.: Hydrological model sensitivity to parameter and radar rainfall estimation uncertainty, Hydrol. Process., 18, 3277-3299, doi:10.1002/hyp.5659, 2004.

Ivanov, V. I., Vivoni, E. R., Bras, R. L., and Entekhabi, D.: Catchment hydrologic response with a fully distributed triangulated irregular network model, Water Resour. Res., 40, W11102, doi:10.1029/2004WR003218, 2004.

Kalogiros, J., Anagnostou, M. N., Anagnostou, E. N., Montopoli, M., Picciotti, E., and Marzano, F. S.: Optimum estimation of rain microphysical parameters using X-band dualpolarization radar observables, IEEE Trans. Geosci. Remote Sens., doi:10.1109/TGRS.2012.2211606, online first, 2012a.

Kalogiros, J., Anagnostou, M. N., Anagnostou, E. N., Montopoli, M., Picciotti, E., and Marzano, F. S.: Evaluation of a new polarimetric algorithm for rain path attenuation correction of X-band radar observations against disdrometer data, IEEE Geosci. Remote Sens. Lett., doi:10.1109/TGRS.2013.2250979, online first, 2012b.

Kalogiros, J., Anagnostou, M. N., Anagnostou, E. N., Montopoli, M., Picciotti, E., and Marzano, F. S.: Correction of polarimetric radar reflectivity measurements and rainfall estimates for apparent vertical profile in stratiform rain, J. Appl. Meteor. Climate, doi:10.1175/JAMC-D-12-0140.1, online first, 2012c.

Leuenberger, D. and Rossa, A.: Revisiting the latent heat nudging scheme for the rainfall assimilation of a simulated convective storm, Meteorol. Atmos. Phys., 98, 195-215, 2007.

Marzano, F. S., Picciotti, E., and Vulpiani, G.: "Rain field and reflectivity vertical profile reconstruction from C-band radar volumetric data", IEEE Trans. Geosci. Rem. Sens., 42, 1033-1046, 2004.

Marzano, F. S., Scaranari, D., Vulpiani, G., and Montopoli, M.: Supervised classification and estimation of hydrometeors using Cband dual-polarized radars: a Bayesian approach, IEEE Trans. Geosci. Remote. Sens., 46, 85-98, 2008.

Marzano, F. S., Botta, G., and Montopoli, M.: Iterative Bayesian Retrieval of Hydrometeor Content from X-band Polarimetric Weather Radar, IEEE Trans. Geosci. Remote. Sens., 48, 30593074, 2010.

Matrosov, S., Kingsmill, D. E., Martner, B. E., and Ralph, F. M.: The Utility of X-Band Polarimetric Radar for Continuous Quantitative Estimates of Rainfall Parameters, J. Hydrometeorol., 6, 248-262, 2005.
Matrosov, S., Clark, K., Martner, B., and Tokay A.: X-band polarimetric radar measurements of rainfall, J. Appl. Meteor., 41, 941952, 2002.

Meischner, P., Collier, C., Illingworth, A., Joss, J., and Randeu, W.: Advanced Weather Radar Systems in Europe: The COST 75 Action, B Am. Meteorol. Soc., 78, 1411-1430, 1997.

Montopoli, M., Picciotti, E., Di Fabio, S., Telleschi, A., Volpi, A., and Marzano, F. S.: X-band weather radar monitoring of precipitation fields at urban scale: spatial calibration and accuracy evaluation, Proceeding of the 6th European conference on radar in meteorology and hydrology ERAD 2010, Sibiu (Romania), 2010.

Park, S., Maki, M., Iwanami, K., Bringi, V., and Chandrasekar, V.: Correction of radar reflectivity and differential reflectivity for rain attenuation at X-band, Part II: Evaluation and application, J. Atmos. Ocean. Technol., 22, 1633-1655, 2005

Picciotti, E., Marzano, F. S., Cinque, G., Montopoli, M., Bernardini, L., De Sanctis, K.,. Anagnostou, E., Kalogiros, J., Anagnostou, M., Fessas, Y., Volpi, A., Telleschi, A., Cazac, V., and Pace, R.: Exploiting X-band dual-polarization mini-radar network and hydro-meteorological forecast models in Moldova territory during the field campaign of HYDRORAD project. Proceeding of the 7th European Conference on Radar in Meteorology and Hydrology (ERAD), Toulouse, France, 25-29 June 2012, 2012.

Rossa, A., Laudanna Del Guerra, F., Borga, M., Zanon, F., Settin, T., and Leuenberger, D.: Radar-driven Highresolution Hydro-meteorological Forecasts of the 26 September 2007 Venice Flash Flood, J. Hydrol., 394, 230-244, doi:10.1016/j.jhydrol.2010.08.035, 2010.

Steiner, M., Houze, J. R. A., and Yuter, S. E.: Climatological characterization of three-dimensional storm structure from operational radar and rain gauge data, J. Appl. Meteor., 34, 1978-2007, 1995.

Testud, J., Le Bouar, E., Obligis, E., and Ali-Mehenni, M.: The rain profiling algorithm applied to polarimetric weather radar, J. Atmos. Ocean. Technol., 17, 332-356, 2000.

USACE: "Hydrologic Modeling System HEC-HMS User's Manual Version 3.5." US Army Corps of Engineers, Hydrologic Engineering Center, Davis, CA, USA, August 2010.

Ventura, J., Boumahmoud, A.-A., Fradon, B., Dupuy, P., and Tabary, P.: Long-term monitoring of French polarimetric radar data quality and evaluation of several polarimetric quantitative precipitation estimators in ideal conditions for operational implementation at C-band, Q. J. R. Meteorol. Soc., doi:10.1002/qj.1934, online first, 2012.

Vulpiani, G., Marzano, F. S., Chandrasekar, V., and Lim, S.: Constrained iterative technique with embedded neural network for dual-polarization radar correction of rain path attenuation, IEEE Trans. Geosci. Rem. Sens., 43, 2305-2314, 2005.

Zrnic, D. and Ryzhkov, A. V.: Polarimetry for Weather Surveillance Radars, B. Am. Meteorol. Soc., 80, 389-406, 1999. 